\title{
Exploring the Future of Public-Private eGovernment Service Delivery
}

\author{
Rex Arendsen, Marc. J. Ter Hedde, and Hanneke Hermsen \\ Centre for eGovernment Studies, University of Twente, P.O. Box 217, \\ 7500 AE Enschede, The Netherlands \\ Dutch Tax Administration, Centre for Professional Development \\ and Communication, P.O. Box 18200, 3501 CE Utrecht, the Netherlands \\ r.arendsen@minfin.nl, m.j.terhedde@gw.utwente.nl, \\ a.j.m.hermsen@belastingdienst.nl
}

\begin{abstract}
Intermediary service providers are important users and actors of eGovernment. This paper explores future longer-term collaborative models and partnerships between the public sector and divers new intermediaries. Four distinguished and logical scenarios of public-private cooperation around 2015 have been developed. Each 'extrema' presents a plausible future and specific implications and effects regarding the future role and position of the intermediary (e-)service providers. Whereas the current state-of-the-art shows a wide variety of intermediate roles, each of the future scenarios tends to stress one specific role. Being prepared for these futures is a major competitive advantage. The scenarios present the framework for assessing the impact of societal trends and present a test bed for the design of future-proof eGovernment strategies.
\end{abstract}

Keywords: eGovernment, Intermediary Service Providers, Scenario Building.

\section{Introduction}

Intermediary service providers are important users and actors of eGovernment. Personal income tax filing for instance is being supported by social intermediaries like unions or elderly organizations. Especially small and medium sized businesses (SME's) decide to outsource administrative, secondary processes. Shipping agencies for example take care of customs declarations, book-keepers fill in and send business tax notices of assessment and salary service organizations calculate and pay social security contributions and report to the statistical department [1]. In many countries nowadays these intermediary service providers have become part of a broader eGovernment multi channel service delivery strategy [2], [3].

The role of intermediaries in eGovernment service delivery and governance has been addressed as a key area of eGovernment-specific socio-economic research challenges. Thus addressing the need to better understand and consider the needs of these intermediaries as both users and actors of eGovernment [4]. Numerous contemporary policy discussions and technological developments will influence intermediary service providers ' future position and role with respect to eGovernment services delivery. 
Outcomes of the policy debate regarding the capacity of the state and the development of alternative mechanisms for exerting control over society might effect current trade offs within public-private arrangements. At the extreme for example it has been argued that 'governance without government' will become the dominant pattern of management for advanced industrial democracies [5].

Implementation of structural legal and administrative reforms will effect the intermediary's business case. It has been argued that currently an 'intermediary paradox' is preventing individual businesses to profit directly from the reduction of administrative burdens [6].

The Internet and different ICT's enable direct contact between organizations and their clients and lower transactions cost. Growing competition and innovation within the administrative services industry itself may result in the removal of the intermediary role in the services delivery channel [7].

Caused by low adoption rates of eGovernment services a growing number of countries chose mandatory implementation strategies for e-taxation and e-invoicing services [8]. Analysis of the Dutch legal obligation of e-taxation for businesses indicates as a result a strengthening of the intermediary's position [1].

What might be the result of these discussions and technological developments over time, and towards what kind of public-private partnerships might this evolve? This paper explores these possible longer-term collaborative models and partnerships between the public sector and divers new intermediaries, which could help governments and private parties to respond to changing technologies and opportunities [9]. Scenario building has been used as a methodology to address future issues and to incorporate both private and public stakeholders in the research process.

The article proceeds as follows. First, the current state-of-the-art is analysed in the next paragraph. Then, the scenario building research methodology and its application to the specific case is illustrated briefly. The resulting four future scenarios are then introduced. Each scenario presents a possible future of the position of intermediary organizations with respect to the delivery of eGovernment services to businesses in the Netherlands. The time horizon was set at about the year 2015. Finally, this paper sketches the most manifest policy implications for the development of public-private cooperation.

\section{State-of-the-Art}

On the one hand private sector intermediaries have been introduced by governments within delivery processes of public services. These government commissioned intermediaries [10] deliver services on behalf of governmental organizations. Post offices for example may facilitate the issuing of drivers licences whereas notaries transfer cadastral data. ICT has enabled the outsourcing of a number of functions traditionally performed by the public bureaucracy to private sector companies.

On the other hand citizens and businesses decide to outsource activities to commercial intermediary service providers. These customer commissioned intermediaries [10] provide a broad range of administrative and advisory services, which in most cases includes the inherent data reporting relationship with governmental organizations. This study has been focussed on the role of customer commissioned intermediaries providing eGovernment services to businesses. 
Intermediaries provide many functions and roles that cannot be easily replaced, substituted or internalized through direct interactions. Four roles of intermediaries can be defined [1], [11], [12], [13]:

- $\quad$ matching demand and supply: bridging the gap between the service requestor's wishes and requirements and the service provider's offers;

- information processing: acquiring, aggregating and distributing data;

- providing trust: ensuring the accountability of decisions;

- $\quad$ providing interoperability: managing an institutional infrastructure used by multiple organizations.

Within the administrative data processing context of eGovernment these roles often overlap. For those who are not online for example, an intermediary can conduct eGovernment on their behalf. Thus bridging the gap between the demand and supply on the one hand and providing interoperability on the other hand [10].

Matching demand and supply. Individual businesses have the choice either to implement direct electronic relationships with governmental organizations or to outsource these interactions to intermediary service providers. The UK Office of the e-Envoy [10] states that due to their existing relationships with customers and insight into their needs, intermediaries are well placed to deliver effective eGovernment services in a customer-centric way. Agulnik [14] illustrates that intermediaries are more likely to get people to claim online, because they provide more customerfocused services and are better placed to reach the digitally excluded. "The US Government believes a partnership with private industry will provide taxpayers with higher quality services by using the existing expertise of the private sector; maximize consumer choice; promote competition within the marketplace; and meet objectives in the least costly manner to taxpayers". Researcher hypothesise that the introduction of ICT will influence the market of intermediary e-services causing a disintermediation process as result of which traditional intermediary organizations will sooner or later disappear [15], [16]. These disintermediation arguments are mainly based on reducing the cost of services transactions [17], [7]. On the other hand researchers expect new intermediaries to enter these markets, taking advantage of new market characteristics and delivering new added value services, resulting in (re-)intermediation [18], [19].

Information processing. The majority of the administrative business-to-government services originate from legal information obligations. Businesses are enforced to report data regarding their personnel, turnover, production processes, etcetera. These reporting costs are an administrative burden to many businesses. Allers [20], defines this administrative burden as "compliance cost: private sector costs of complying with regulations". Many European countries, amongst which the Netherlands, position eGovernment as a way to reduce this administrative burden of businesses [21]. Caused by the complexity, scale and diversity of these information obligations many SME's chose however to outsource this data reporting to governmental organizations. Contrary to most individual SME's, many of these intermediary service providers are able to gain efficiency benefits from electronic data reporting relationships with governmental organizations. A professional (ICT-) organization enables them to profit from economies of scale and to benefit from the so called electronic integration effect [15]. 
Providing trust. Sarkar et al. [22] point to the fact that trust may enforce the intermediary's position; users are likely to perceive intermediaries to be on their side. Intermediaries can enhance trust by reducing the risk of failures within the transaction process chain and are able to assure that transactions between commercial partners have been completed [11]. An intermediary as a 'trusted third party', may provide legal cont(r)acts between parties, providing the authentication and integrity of the communication needed within inter-organizational relationships. The notary is an example of such a legally institutionalised trusted third party.

Providing interoperability. Interoperability is defined as "the ability of ICT systems and supported business processes to exchange data and by that to share information and knowledge" [23]. Communication services providers primarily focus on the logistics part of electronic message interchange, as for instance the routing, archiving and tracking and tracing of data [6]. These hubs provide network services like availability, security and capacity. Those intermediaries can play a major role in the adoption and diffusion process by helping to standardise the technologies that are used to deliver e-services [24]. Next to that, not everyone will have access to electronic public services, particularly in rural areas [4] and developing countries; intermediaries can "bridge the gap between e-government implementation and social reality ... and play an important role in the diffusion of e-services in relation to improving the availability, accessibility and enhancing privacy and security in a developing country" [25]. The business services providers' added value lies in the decoupling of business processes and message handling of organizations involved. This group of service providers consists amongst others of traditional book-keepers and advisors to which administrative task are being outsourced. New types of business service providers arise, like the application service providers (ASP's) which in general provide business functions via the Internet.

In what way might future developments influence trade-off's between these four functions and roles? Will one role prevail over the others? Unexpected cooperation between different types of intermediary service providers, hard- and software suppliers for instance will influence the future market of governmental e-services delivery [6]. The next paragraphs explore what the future may look like.

\section{Research Method}

In this study we applied the method of explorative scenario thinking. This structured approach does not try to eliminate uncertainty or tries to predict what is merely unpredictable, but on the contrary underlines uncertainties and ambiguity of the future. This relates to the fact that strategic decision making takes place within a context of uncertainty about the future.

Scenario building is a widely used future research method and a not uncommon method in eGovernment research [26]. In general there are different approaches of constructing and using scenarios. Some scenarios are an extrapolation of current trends (extrapolative approach), usually resulting in three scenarios: a positive, middle and negative option. Other types of scenarios present a desirable future (normative scenarios) or are the result of desk research or trend watching. 
The scenario building method used in our research strongly differs from forecasting. While forecasting predicts the near future based on the extrapolation of past and current developments, scenario building cuts off the past and requires us to look solely into the future. It helps to gain more insight into possible future developments. The scenarios are neutral: they are neither good nor bad futures [27].

\section{Scenario development process}

The explorative scenarios have been developed according to the following process:

1. Identifying (un)certainties. The process starts with the identification of the most important trends and developments (driving forces) within the social, economic, institutional and organizational domain. Next, these driving forces are ordered according to their impact on the organization under consideration (i.c. the intermediary services channel) as well as according to their relative uncertainty.

2. Identifying scenario axes: Based on a 'trial and error process' the two most important uncertainties are determined. That is, the two most uncertain driving forces which are assessed to have the highest impact on the organization. These driving forces need to be independent of each other and when crossed, result in four clearly distinguished scenarios.

The result of these first two steps are presented in paragraph 4 .

3. Developing the story lines. The third process step starts with the description of the end positions of the four scenarios. This means that four distinguished, plausible and logical coherent stories of the relevant environment in 2015 are created. Next, these stories are linked to the present by hypothetical events that need to take place in order for the end states to be developed. In this way each scenario has a beginning (the present), a middle and an end.

4. Wind-tunneling the scenarios. During this process step the scenarios are being used as a test bed of the future. In this case implications and effects of each scenario on the future role and position of the intermediary service providers have been analyzed.

The result of the third and fourth process steps are presented in paragraph 5 .

5. Strategy development. During the last step different strategic options are generated for each scenario answering the question: "What would we want to do if this was how the real world would be developing?". In the final phase the options are then analyzed across all scenarios in order to improve them towards a robust strategy applicable in all four scenarios. Results of this final step are discussed in paragraphs 6 and 7.

\section{Workshops and participants}

Creativity and conflicting subjective opinions by (possibly biased) humans are important ingredients of scenario building methods. The scenarios in this study have been developed during four separate workshop sessions. The actual scenario building has been executed by business and governmental professionals and scientists familiar with public-private eGovernment service delivery. During the research project 25 experts participated, residing from: several accountancy organizations, commercial communication service providers within the agricultural and the logistics domain, ecommerce and ICT standardisation organizations, the Tax and Customs Administration, the Social Security Agency, the Ministry's of Finance and Economical Affairs and Dutch universities. 
The individual workshop sessions were organised by a small project group and were facilitated by scenario building experts who assured the methodological quality of the process. The project group prepared and finalized the workshop documents. As a starting point of the brainstorms during the first workshops a long list of trends and driving forces has been produced based on desk research. The raw workshop results were captured and summarized into formal workshop documents.

During each workshop one or two process steps have been executed. Groups of five to six participants, moderated by a coach, produced results that were validated and/or enriched by other expert groups thus ensuring and stimulating a creative and goal oriented process. This iterative engineering process and the contribution of independent, multi-disciplinary experts support the validity of the workshop results. Next to that, as part of the final plenary strategic session, a new group of experts assessed the content validity and logical consistency of the scenario's.

\section{Results: Key Uncertainties and Scenario-Axes}

The first two steps of the scenario development process resulted in the two most uncertain driving forces which are assessed to have the highest impact on the organization under consideration (i.c. the intermediary services channel). These two most uncertain driving forces result in contradictory and alternative futures and thus feed into four clearly distinguished scenarios. This opposite to 'certain' societal developments relevant in every scenario, like the altering demographic characteristics of the Netherlands and the ongoing digitalisation. With respect to this research objective, the exploration of possible longer-term collaborative models and partnerships between the public sector and divers new intermediaries, the two key uncertainties are:

- $\quad$ Trust in government (high or low). The extent to which society (citizens and businesses) have confidence in politics, municipalities, provinces, benefit agencies, etc. In case of high trust, people perceive government acts honestly, driven by high moral standards. In case of low trust people doubt governments intentions.

- $\quad$ The organization of society (limited versus unlimited). This aspect addresses the way private persons, businesses and/or organizations/communities live and work together. In the 'limited society' uniformity and cost efficiency prevails. The 'one size fits all' mentality is based on rational economic motives which set boundaries to the freedom of choice. On the contrary, in the 'infinite, unlimited society', rational-economic drivers are less dominant. Personal motives and the desires to distinguish oneself fuel social processes.

These two key uncertainties define the four scenarios of public-private collaborative models. Trust in government on the vertical axis and Organization of society on the horizontal axis result into the four quadrants presented in figure 1. 


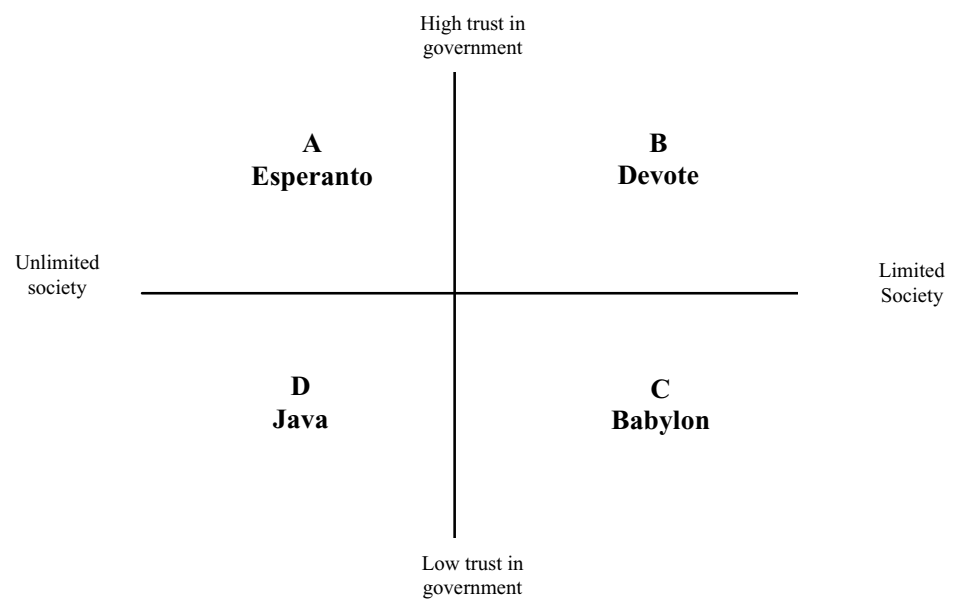

Fig. 1. The Uncertainties and Scenarios

We chose to name the scenarios after linguistic phenomena; stressing the importance of the aspect of communication and cooperation in each of the scenarios. These titles should help to grasp the meaning of each of the scenarios and to distinguish it from the others.

Esperanto, one language bridging differences, opposite to Babylon, referring to 'a perfect Babel' where no one understands the other.

Devote referring to be set apart and strongly affected to dedicate by a solemn act; (in the Netherlands also referring to a software company specialized in custom made software), opposite to Java, a public license, cross platform, software language.

\section{Results: The Four Scenarios}

This paragraph presents in sum the four distinguished, plausible and logical scenarios of public-private cooperation around 2015. The scenarios are presented as 'extrema' in order to contrast with each other. Each description starts with a short coherent storyline of the relevant environment, characterized in terms of political, social, and/or economical themes. Next, implications and effects of each scenario regarding the future role and position of the intermediary (e-)service providers are being highlighted.

\section{Scenario Esperanto}

The scenario Esperanto presents a safe and high trust society. Security is a political top priority surpassing privacy. Persons and organizations focus on cooperation within changing collaborative models. Both citizens and businesses are compliant and prefer high trust relationships with government. They are however very demanding regarding the quality, flexibility and speed of governmental e-service delivery. People prefer to work for themselves or within private companies in stead of being a civil servant. Confronted with many employees retiring, most governmental organizations face human resource shortages. Sustainable innovation is a top priority of many non 
governmental organizations. Cooperation between European member states is close. This and the continuing globalisation empowers the Dutch open economy. Pushed by a growing spread of Internet applications services, ICT has become an integrated part of daily life. Esperanto pictures a world connected by open standards facilitating common understanding.

Implications and effects. Intermediaries intensify their relationships with governmental organizations. On the one hand forced by growing direct high trust relationships between individual businesses and government, on the other hand stimulated by growing governmental personnel shortages. These intermediaries become co-producers of electronic governmental services realizing substantial cost savings in the complete life cycle of governmental e-services. Using their former information and network position intermediaries are able to deliver custom-made, highly personalized services. To be able to cope with the growing number of (often project based) cooperative models, intermediaries try to specialize. They organize into groups of similar business partners in search for market influence or dominance.

\section{Scenario Devote}

The scenario Devote presents a society focused on self interest. Citizens more often feel unsafe and ask for more police and strict law enforcement. Citizens perceive high trust in government and its civil servants. By consequence, governmental organizations are in the position to formulate and execute policies regarding a broad range of societal issues. On the contrary, people have lost their faith in commercial organizations. The financial and economical crisis has undermined their legitimacy. Empowered by the application of new sustainable technologies governmental institutions have become well organised, efficient organizations. They do not experience any problems in finding new and qualified personnel. These organizations are now the driving force behind large innovative, former commercial, projects like for instance the establishment of wind energy parks in the North Sea. Stimulated by the European Commission specific national digitalisation programs are being implemented, focussing on efficient and uniform local e-service delivery.

Implications and effects. Within this scenario the intermediary's network position worsens very rapidly. A lack of trust undermines their independent commercial market position towards individual customers. On the other hand governmental organizations are able and capable to standardize e-service delivery. Thus resulting in as 'one size fits all'- quality of service accepted by citizens and businesses. On the operational level intermediary organizations will provide 'neutral' data processing capacity, labeled as extensions of government. Groups of intermediaries negotiate strategic alliances together with groups of governmental organizations. This high level cooperation aims at knowledge transfer and agenda setting in order to regain trust and define and develop new business.

\section{Scenario Babylon}

The scenario Babylon presents a society of communities. Citizens are pretty much self-reliant, have a low confidence in government and offer resistance to governmental interventions. Citizens prevail 'small scale' and 'home town', primarily 
focusing on national regions rather than on global or European cooperation. Protectionist trade barriers slow down innovation and globalization. As a result the open Dutch economy is in recession. Group identity empowers its members. Elderly people for instance organize into communities, protecting their own interests and creating their own services organization. Consensus is no longer the obvious political strategy, but each group strives for the realization of specific interests. Society is less interested and less in need of generic governmental service delivery. Governmental influence diminishes towards law enforcement issues and free market regulation. Government regulates the bargaining space between the different societal 'blocks' (groups of citizens and businesses) and defends transcending national interests.

Implications and effects. Within this scattered society intermediary service providers will become the glue between different societal groups. These groups are niche markets to commercial service providers. Some intermediary organizations have become the group's sole representative and data gateway in connection to other groups. Providing interoperability is their core competence. Towards government, these intermediaries represent the group and provide specific eGovernment services towards individual group members, citizens and businesses. A small number of strategic alliances dominates the market of intermediary e-services and defines and regulates the 'glue infrastructure'. This group of alliances is the negotiating party towards government and other industry groups.

\section{Scenario Java}

The scenario Java describes a scattered society in which citizens and businesses have a low level of trust in government. Citizens have to be self-reliant and focus on personal interests. Personal motives and the desires to distinguish oneself fuel social processes. As a result of increased international mobility, foreign employees have now become a familiar phenomenon in Dutch society. Numerous ICT applications enable businesses and citizens to interact and organize in different ways. $e$ Communities are the new pillars of society. Service delivery and production are increasingly organized in a project based manner. Within these projects and communities people and organizations temporarily unite private interest to realize common objectives. Government concentrates on a few basic policy domains like security and defense. If possible other governmental tasks are being outsourced to private companies.

Implications and effects. Within this scattered society trust provision is scarce but vital. Neither government nor societal groups are trustworthy or stable enough. Independent intermediary organizations will become the dominant societal trust providers. Their service delivery may even be extended towards other domains of common interest like insurance, finance, and social security. In that way intermediary service providers will become the dominant communication and service channel towards individual citizens and businesses. However, the perceived quality of intermediate service delivery heavily depends on the providers ability to customize and personalize transactions. Volatile e-communities ask for an agile organization of service delivery, and demanding individuals can only be satisfied by means of customer intimacy. 


\section{Conclusions}

This paper's objective is to present possible future, innovative and longer-term, collaborative models and partnerships between the public sector and divers new intermediaries, which could help governments and private parties to respond to changing technologies and opportunities. Table 1 summarized the four scenarios developed in this study, from an intermediary's viewpoint.

Table 1. Scenarios for Future Public-Private Collaboration

\begin{tabular}{|l|l|l|l|l|}
\hline Scenario: & Esperanto & Devote & Babylon & Java \\
\hline $\begin{array}{l}\text { Trust in } \\
\text { government }\end{array}$ & High & High & Low & Low \\
\hline Openness society & No frontiers & Limited & Limited & No frontiers \\
\hline $\begin{array}{l}\text { Intermediary } \\
\text { relation to } \\
\text { government }\end{array}$ & $\begin{array}{l}\text { Co-producer of } \\
\text { eGovernment } \\
\text { services }\end{array}$ & $\begin{array}{l}\text { Strategic, high } \\
\text { level partnerships } \\
\text { on sector level }\end{array}$ & $\begin{array}{l}\text { Distant business } \\
\text { representative }\end{array}$ & $\begin{array}{l}\text { Communication } \\
\text { channel towards } \\
\text { businesses }\end{array}$ \\
\hline $\begin{array}{l}\text { Relation to } \\
\text { customers }\end{array}$ & Distant & Distant & $\begin{array}{l}\text { eGovernment } \\
\text { services provider }\end{array}$ & High trust provider \\
\hline $\begin{array}{l}\text { Added value } \\
\text { Intermediary } \\
\text { business model }\end{array}$ & $\begin{array}{l}\text { Cost saving for } \\
\text { government }\end{array}$ & $\begin{array}{l}\text { Low, primarily } \\
\text { data processing }\end{array}$ & $\begin{array}{l}\text { Specific niche } \\
\text { services }\end{array}$ & $\begin{array}{l}\text { Risk management } \\
\text { and trust provision }\end{array}$ \\
\hline $\begin{array}{l}\text { Dominant role } \\
\text { and function. }\end{array}$ & Demand-supply & $\begin{array}{l}\text { Neutral } \\
\text { information } \\
\text { processing }\end{array}$ & $\begin{array}{l}\text { Interoperability } \\
\text { between power } \\
\text { centers }\end{array}$ & $\begin{array}{l}\text { Customer intimacy } \\
\text { and services } \\
\text { operational } \\
\text { interoperability }\end{array}$ \\
\hline
\end{tabular}

Each of the four scenarios presents a different modus of public-private cooperation; some of which are potentially threatening to commercial service providers, others tempting and full of commercial opportunities. Some scenarios present omni present and well appreciated eGovernment services, in others eGovernment in hidden behind commercial intermediaries. The most provoking conclusion is perhaps the fact that each scenario presents a plausible, possible future. Independent of our personal or organizational interests and plans, future society might develop in one of these (neither 'good', nor 'bad') directions.

One of the most interesting findings concerns the intermediary's future role and function. Whereas the current state-of-the-art shows a wide variety of intermediate role's, each of the future scenarios tends to stress one specific role. The same holds for the dominant type of e-service delivery; varying from servicing private ecommunities to the co-production of eGovernment services.

Being prepared for these futures is a major competitive advantage. These scenarios present the framework for assessing the impact of societal trends and present a test bed for the design of future-proof eGovernment strategies.

An important critical success factor has been the role of the independent facilitators who assured the result's objectivity and plausibility. Whereas each participant in the research project had its own perception of a desired future, based on personal feelings and organizational interests, the method of scenario building inspired the group to look frankly into the future. 


\section{Discussion}

What would we want to do if this was how the real world would be developing?" This question is the starting point from which organizations can begin with the assessment of their current eGovernment strategy. Each scenario presents a different view on the role of open standards, multi channel strategies, the quality of service and strategic partnerships.

Regardless of which scenario will deploy at the end, two organizational aspects are crucial in each transition process: agility and the ability to establish strategic alliances. These two organizational characteristic are critical success factors for the future 'survival of the fittest'. Each scenario presents a change in activities, responsibilities and inter-organizational relationships.

The process of change starts with the awareness that each organization is part of the changing network towards one of the possible scenarios presented in this paper.

\section{References}

1. Arendsen, R., Ter Hedde, M.: On the Origin of Intermediary E-Government Services. In: Wimmer, M.A., Scholl, H.J., Janssen, M., Traunmüller, R. (eds.) EGOV 2009. LNCS, vol. 5693, pp. 270-281. Springer, Heidelberg (2009)

2. Pieterson, W.J.: Channel Choice. Twente University, Enschede (2009)

3. Klievink, B., Jansen, M.: Coordinating e-government service delivery. In: Proceedings of the 11th Annual International Digital Government Research Conference (2010)

4. Centeno, C., Van Bavel, R., Burgelman, J.C.: A Prospective View of e-Government in the European Union. Electronic Journal of e-Government 3(2), 59-66 (2005)

5. Peters, B.G., Pierre, J.: Governance Without Government? Rethinking Public Administration. Journal of Public Administration Research and Theory 8, 223-243 (1998)

6. Arendsen, R.: Geen Bericht, Goed Bericht. English summary included. University of Amsterdam, Amsterdam (2008)

7. Janssen, M., Klievink, B.: The Role Of Intermediaries In The Multi-Channel Services Delivery Strategies. International Journal Of E-Government Research 5(3), 36-46 (2009)

8. Agostini, P.L., Naggi, R.: B2G Electronic Invoicing as Enforced High Impact Service: Open Issues. In: D’Atri, A., Saccà, D. (eds.) Information Systems: People, Organizations, Institutions, and Technologies. Springer, Heidelberg (2010)

9. OECD: The e-Government imperative main findings. Policy Brief (2003)

10. Office of the e-Envoy: Policy Framework for a mixed economy in the supply of egovernment services. A Consultation Document (2003)

11. Bailley, J.P., Bakos, J.Y.: An Exploratory Study of the Emerging Role of Electronic Intermediaries. International Journal of Electronic Commerce 1(3), 7-20 (1997)

12. Janssen, M., Sol, H.G.: Evaluating the role of intermediaries in the electronic value chain. Internet Research. Electronic Networking Applications and Policy 19, 5 (2000)

13. Janssen, M., Klievink, B.: Do We Need Intermediaries in E-Government? In: Proceedings of the Fourteenth Americas Conference on Information Systems, Canada (2008)

14. Agulnik, P.: Claiming state benefits online: the role of intermediaries. Entitled (2010) 
15. Malone, T.W., Yates, J., Benjamin, R.I.: Electronic Markets and Electronic Hierarchies. Communications of the ACM 30, 6 (1987)

16. Chircu, A.M., Kauffman, R.J.: Strategies for Internet Middlemen in the IDR Cycle. The International Journal of Electronic Commerce and Business Media (1999)

17. Gellman, R.: Disintermediation and the internet. Government Information Quarterly 13(1), 1-8 (1996)

18. Clemons, E.K., Reddi, S.P., Row, M.C.: The Impact of Information Technology on the Organization of Economic Activity. Journal of Management Information Systems (1993)

19. Klievink, B., Janssen, M.: Improving Government service delivery with private sector intermediaries. European Journal of ePractice 5 (2008)

20. Allers, M.A.: Administrative and Compliance Costs of Taxation and Public Transfers in the Netherlands. Rijksuniversiteit Groningen (1994)

21. OECD: Netherlands, OECD e-Government Studies. Organisation for Economic Cooperation and Development (2007)

22. Sarkar, M.B., Butler, B., Steinfield, C.: Intermediaries and Cybermediaries. Journal of Computer-Mediated Communication 1 (1995)

23. IDABC: European Interoperability Framework for pan-European eGovernment Services. European Commission, 2004/2094, Luxembourg (2004) ISBN 92-894-8389-X

24. Howells, J.: Intermediation and the role of intermediaries in innovation. Research Policy 35, 715-728 (2008)

25. Al-Sobhi, F., Weerakkody, V., Al-Shafi, S.: The Role of Intermediaries In Facilitating EGovernment Diffusion in Saudi Arabia. In: Proceedings of the EMCIS (2010)

26. Duin, P., Huijboom, N.: The futures of EU-based eGovernment: a scenario-based exploration. In: Proceedings of the 41st HICSS (2008)

27. Bicking, M., Janssen, M., Wimmer, M.A.: Looking into the future: scenario's for egovernment in 2020. In: Suomi, R. (ed.) IFIP, vol. 226, pp. 392-404 (2006) 